\title{
The prevalence of self-reported chronic fatigue in a U.S. twin registry
}

\author{
Helena Furberg ${ }^{a}$, Megan Olarte $^{a}$, Niloo Afari $^{b}$, Jack Goldberg $^{c}$, Dedra Buchwald ${ }^{d}$, and Patrick \\ F. Sullivan ${ }^{\mathrm{a}}{ }^{*}$ \\ aDepartment of Genetics, University of North Carolina, Chapel Hill, NC, USA \\ ${ }^{b}$ Department of Psychiatry and Behavioral Sciences, University of Washington, Seattle, WA, USA \\ 'Department of Epidemiology, University of Washington \& Vietnam Era Twin Registry, Seattle, WA, \\ USA \\ dDepartment of Medicine, University of Washington School of Medicine, Seattle, WA, USA
}

\begin{abstract}
Objective-To investigate the prevalence and correlates of various definitions of self-reported lifetime fatiguing illness in a U.S. twin registry.

Methods-Data from 4591 female and male twins from the population-based Mid-Atlantic Twin Registry were available for this study. Variables representing different definitions of lifetime fatiguing illness and personal characteristics were obtained through questionnaires. Odds ratios and 95\% confidence intervals were calculated as measures of association between fatigue and gender. Kaplan-Meier curves were produced to examine the age at onset for lifetime fatiguing illnesses.

Results-Prevalences for different definitions of self-reported lifetime fatigue ranged from $36.7 \%$ for any fatigue to $2.7 \%$ for chronic fatigue syndrome-like illness. Females were two to three times more likely to report fatigue than males. Gender differences increased as fatigue definitions grew more restrictive. Ages at onset of chronic fatiguing illness were significantly earlier and the number of ancillary symptoms was greater for females than males. People with lifetime fatigue had significantly more compromised functional status than people without lifetime fatigue.
\end{abstract}

Conclusion-The prevalence of self-reported lifetime fatiguing illness varied widely depending upon how it was defined. Given the debilitating consequences of fatiguing illnesses, the reasons for the female predominance and the earlier onset in women should receive increased research priority.

\section{Keywords}

Chronic fatigue; Fatiguing illness; Prevalence; Gender

\section{Introduction}

Chronic fatigue syndrome (CFS) lies on the extreme end of a spectrum of fatiguing conditions. Some degree of fatigue is a common and usually transient symptom [1-3], whereas CFS is rare $[4,5]$ and generally associated with marked functional impairment [6-9].

(c) 2005 Elsevier Inc. All rights reserved.

*Corresponding author. Tel.: +1 919966 3358; fax: +1 919966 3630. pfsulliv@med.unc.edu. . 
Several epidemiological studies have investigated the prevalence of CFS and related fatiguing conditions. Two population-based surveys used a multistage procedure based on random-digit dialing to screen subjects followed by confirmatory clinical examinations. The prevalence of CFS was $0.422 \%$ (95\% confidence interval [CIs] 0.29-0.56\%) in the Chicago area [4] and $0.235 \%$ (95\% CI 0.14-0.33\%) in Wichita, KS [5]. However, both studies had low partic-ipation rates in the clinical examination phase ( $41 \%$ and $54 \%)$. Population-based studies of CFS-like illnesses also have been conducted where individuals meet the criteria for CFS based on questionnaires and/or interviews but do not undergo the requisite clinical evaluation. Studies based on questionnaire assessments of CFS yielded current prevalences in the 2-3\% range $[10,11]$, whereas studies using interviews observed considerably lower rates $(0.007 \%$ and $0.23 \%)[12,13]$. Many studies on the prevalence of CFS have used clinically ascertained samples. The median prevalence estimate in these studies was $0.3 \%$, although the range was of extraordinary breadth $(0.04-2.6 \%)[6,14-19]$. It is likely that these clinical samples are not representative of the total population of individuals with CFS [3,20,21].

We undertook an epidemiological investigation of self-reported fatiguing illness in a population-based twin registry. We screened over 4500 participants for information on fatiguing conditions. Our goals for this report were (a) to report the lifetime prevalence of various definitions of fatiguing illness; (b) to examine the distributions of fatiguing illness by gender; (c) to describe the demographic and personal characteristics associated with different types of fatiguing illnesses; and (d) to evaluate age at onset of different types of fatiguing illnesses separately for males and females.

\section{Methods}

\section{Sample}

All potential subjects were participants in the Mid-Atlantic Twin Registry (MATR) [22]. The MATR is a population-based registry of twin pairs ascertained from birth and school system records of Virginia, North Carolina, and South Carolina. The study protocol was reviewed and approved by Institutional Review Boards (IRB) at Virginia Commonwealth University, the for-profit Western IRB, the University of Washington in Seattle, and the University of North Carolina at Chapel Hill. All subjects provided written informed consent.

\section{Procedures}

We developed a screening questionnaire for lifetime fatiguing illness patterned on the Centers for Disease Control and Prevention 1994 criteria (CDC-94) for CFS [23]. The fatigue section had four stem questions that inquired about lack of energy, tiredness, fatigue, and exhaustion to encompass diverse personal definitions of fatigue. Subjects who reported experiencing any of these symptoms at any point in their lives were then asked a series of additional questions that fell into three domains: degree of social and occupational impairment, eight additional symptoms integral to the CDC-94 definition of CFS (e.g., sore throat, unrefreshing sleep, and difficulty thinking or concentrating), and temporal data (age of onset, duration, and age of offset). Subjects also reported the degree to which they exercise, completed the Short Form-12 Health Survey [24] (SF-12, a widely used assessment of health-related quality of life) and were queried for the criteria for DSM-IV lifetime major depression [25] as assessed by questionnaire [26,27] (this instrument gives similar prevalences and heritability estimates to those determined by personal interview).

We mailed this survey to approximately 15,000 individual participants in the MATR in the last quarter of 1999 and received 4591 responses for a response rate of $31 \%$. This response rate is a minimum as the percentage of individuals who were mailed but never received the survey due to faulty addresses is unknown. Shortly after the initial mailing, all human subjects research 
at Virginia Commonwealth University was halted by the U.S. DHHS Office for Human Research Protections due to concerns about IRB procedures at Virginia Commonwealth University and because of broader/societal privacy concerns related to "secondary subjects" (e.g., in asking a consenting subject about health status of a relative, should the relative be considered a research subject as well?) [28,29]; there were no direct questions about the ethicality of the study reported here. This shutdown lasted for over a year and led to the early termination of this study. It also meant that the available data were limited to the early responders to the survey because the planned repeat mailings, nonresponder telephone followup, reliability substudy, telephone diagnostic interview, and clinical evaluation were not conducted. As an additional consequence, zygosity data were available on only a minority of the subjects.

\section{Definitions of fatigue-related conditions}

The definitions we used were loosely patterned after the CDC-94 criteria [23]. The six selfreported definitions are not mutually exclusive and increase in stringency: (1) "any lifetime fatigue" was present when subjects endorsed one or more of the four stem questions; (2) "prolonged fatigue" required a duration of $\geq 1$ month; (3) "chronic fatigue" was defined as $\geq 6$ months of fatigue; (4) chronic fatigue A added the presence of impairment and the presence of $\geq 4$ of 8 specific ancillary symptoms to the definition of chronic fatigue. Impairment was defined as fatigue that caused a substantial reduction in work, school, social, or personal activities; (5) chronic fatigue $B$ was comprised of subjects with chronic fatigue $A$ whose fatigue was not due to exertion, not substantially alleviated by rest, and not lifelong; (6) The most stringent definition—chronic fatigue $\mathrm{C}-$ corresponded to CFS-like illness. This required that subjects meet criteria for chronic fatigue $\mathrm{B}$ and in addition not report a height and weight consistent with morbid obesity (body mass index $\geq 40 \mathrm{~kg} / \mathrm{m}^{2}$ ) or a personal history of medical illnesses that could explain fatigue (e.g., epilepsy, Crohn's disease, ulcerative colitis). Our reason for studying these different definitions was to enable comparing and contrasting the effects of lesser versus greater definitional stringency; in our view, this is both critical and understudied.

To determine functional status, we used the physical and mental health subscales of the SF-12, which we reported as a continuous measure. Values for the SF-12 summary scales range from 0 to 100 , with higher values reflecting better health. Levels of current exercise were obtained by asking participants the number of times they exercised vigorously for at least $20 \mathrm{~min} / \mathrm{week}$, and the number of times they exercised moderately for at least $30 \mathrm{~min} /$ week.

\section{Statistical analyses}

Analyses were conducted with SAS [30] and S-Plus [31]. Logistic regression, with generalized estimating equations to adjust for the nonindependence of members of a twin pair [32], was used to calculate odds ratios (ORs) and 95\% CIs as measures of association between different definitions of fatigue and gender. We used the Kaplan-Meier estimator method to examine the age of onset of fatiguing illness in females and males [33,34]. Permutation tests were performed to determine empirical significance values that adjusted for the nonindependence of a twin pair. Patterns of missing data did not compromise the interpretations of our findings, as individuals with fatigue were not more likely to be missing data for key variables.

\section{Results}

Fig. 1 depicts the definitions of self-reported lifetime fatigue-related conditions and proportions of study participants who were classified into these groups. Overall, 4591 individual twins who participated in the survey and $64.7 \%$ were female. The prevalence of fatigue-related conditions declined as inclusion criteria into different kinds of fatigue became more stringent. The lifetime 
prevalence of any fatigue in the entire sample was $36.7 \%$, prolonged fatigue $22.5 \%$, and chronic fatigue was $15.7 \%$. The prevalence of chronic fatigue $\mathrm{A}, \mathrm{B}$, and $\mathrm{C}$ were $4.6 \%, 3.6 \%$, and $2.7 \%$, respectively. Fatigue was far more common among female $(75.3 \%)$ than male $(24.7 \%)$ participants. The female predominance in fatigue became more pronounced as stringency of the definition of chronic fatigue increased, with $85.4 \%$ of the chronic fatigue $\mathrm{C}$ group being female.

The upper right histograms in Fig. 1 show the total number of CDC-94 CFS ancillary symptoms for males and females. The mean number of ancillary symptoms was significantly higher for females (mean 1.3, S.D. 2.0) than males (mean 0.7, S.D. 1.5, $P<.0001$ ). Although the CDC-94 criteria for CFS imply a qualitative distinction between fatigued subjects with $0-3$ and 4-8 symptoms, the histograms show relatively smooth quantitative differences.

Fig. 2 depicts the percent of males and females who reported each of the eight symptoms used to further classify chronic fatigue into chronic fatigue A. The final column of the figure shows the gender difference for those participants who reported having $\geq 4$ symptoms. The most common symptom reported by both genders was "unrefreshing sleep".

The self-reported lifetime prevalence of fatigue-related conditions by gender are presented in Table 1, along with ORs and 95\% CIs. Among females, $42.8 \%$ reported any lifetime fatigue, $26.8 \%$ had prolonged fatigue, and $18.6 \%$ were classified with chronic fatigue. The prevalence of chronic fatigue $\mathrm{A}, \mathrm{B}$, and $\mathrm{C}$ among females was $5.7 \%, 4.6 \%$, and $3.5 \%$, respectively. For males, only $25.7 \%$ reported any lifetime fatigue, $14.8 \%$ prolonged fatigue, and $10.4 \%$ chronic fatigue. The lifetime prevalences of chronic fatigue $\mathrm{A}, \mathrm{B}$, and $\mathrm{C}$ were far less common among males (all <3\%) than females. Females were over twice as likely to have chronic fatigue A than males with the ORs increased as the criteria for chronic fatigue $\mathrm{B}$ and $\mathrm{C}$ became more stringent, reaching a maximum of over three for chronic fatigue $\mathrm{C}$. Only about half of females and males reporting chronic fatigue $\mathrm{A}-\mathrm{C}$ were experiencing symptoms at the time of interview (data not shown).

Table 2 describes the characteristics of participants who denied having any lifetime fatigue and who were classified as having a fatigue-related condition. The mean ages at interview were similar for people with and without fatiguing illnesses. The mean number of times participants exercised vigorously for at least $20 \mathrm{~min}$, or exercised moderately for at least $30 \mathrm{~min}$, generally decreased as fatigue-related conditions became more stringent but comparisons between participants with and without fatigue were not statistically significant. The mean SF-12 scores were significantly higher among people with fatiguing illnesses than those without fatigue (all $P$ values <.05). Similarly, the prevalences of recurrent lifetime major depression were significantly higher among people with fatiguing illnesses compared with people with no fatigue (all $P$ values <.001).

Table 3 presents the characteristics of participants who were classified as having a fatiguerelated condition by gender. Within each category of fatiguing illness, females had lower mean ages at interview than males (all $P$ values <.01). Females also reported exercising less often, had lower mean SF-12 mental health scores, and a higher prevalence of recurrent lifetime major depression than males, but gender differences did not reach statistical significance in any fatigue-related category.

The ages at onset curves of chronic fatigue $\mathrm{A}$, chronic fatigue $\mathrm{B}$, and chronic fatigue $\mathrm{C}$ for females and males are shown in Fig. 3. Both genders reported the onset of chronic fatigue A, $\mathrm{B}$, or $\mathrm{C}$ in their early 30s, but females had younger ages of onset than males $(P<.001)$. The median ages at onset for females were 31,32 , and 31 years for chronic fatigue A-C respectively, while for males median ages at onset were $31,33.5$, and 33.5 years. 


\section{Discussion}

Despite the limitations externally imposed on this study (see Methods and discussion of limitations below), there are still relatively few published studies of CFS-like illness that are not based on clinical samples. Therefore, despite the relatively low response rate we achieved, we posit that these data have value and extend the body of knowledge on the epidemiology of self-reported fatiguing illness.

We stress that the response rate to a single mailing achieved in this study (31\%) was a minimum. The mailings were done in a way that did not allow us to know whether the intended respondent actually received the questionnaire. In other words, if an address in the MATR records were incorrect, a potential respondent would not have had the ability to respond. If this occurred for $25 \%$ of the intended respondents, our true response rate would have been in the order of $41 \%$. Moreover, we note that responses to questionnaires have been declining precipitously in the United States and that the low minimum response rate in this study is not distinctive. For example, Kang et al. [35] required three mailings to achieve a 53\% response rate. Informal discussions with epidemiologists in the United States support this general trend.

Consistent with other reports using questionnaires to assess fatigue [10,11], we found that lifetime prolonged fatigue was relatively common whereas CFS-like illness (chronic fatigue $\mathrm{C}$ ), was uncommon. We also found that only about half of the chronic fatigue A, B, and C groups reported experiencing symptoms at the time of interview. Likewise, previous studies using questionnaires have found that the lifetime and current prevalences of CFS-like illness were similar [10,11]. Studies using interviews to assess fatiguing illnesses, however, observed lower rates of current CFS-like illness $(0.007 \%$ and $0.23 \%)[12,13]$ and current CFS $(0.422 \%$ and $0.235 \%)[4,5]$.

These findings suggest that the nearly exclusive focus on current CFS-like illness in the literature may be substantially underestimating the lifetime burden of fatiguing illnesses. Moreover, these findings may have study design implications. As examples, for many types of studies, controls should be required never in their lives to have met criteria for CFS-like illness and, for genetic case-control association studies, ascertainment can be made more efficient by requiring the lifetime presence of CFS or CFS-like illness.

One of the most striking findings of this investigation was the gender difference evident for all of the fatigue-related conditions we assessed. The lifetime prevalences for all definitions of fatiguing illness were greater in females and the ORs for the female-male differences increased as the definitions of fatigue became more restrictive. Of particular interest, the age of onset curves for chronic fatigue A, B, and C were also earlier for females than males. Despite the documentation of these differences in multiple samples, the reasons for these gender differences remain elusive. Women differ from men in multiple ways at the genetic level (different sex chromosomes), in hormonal milieu, and, on average, for exposure to multiple environmental and sociological influences [36,37]. Reasons for the earlier age at onset of chronic fatigue among women should be investigated.

In addition, the total number of ancillary symptoms (given endorsement of any fatigue) was greater for females. In moving from the common symptom of fatigue to the uncommon CFSlike illness, several thresholds are imposed. Notably, many of these thresholds (e.g., the particular ancillary symptoms and $\geq 4$ of 8 required symptoms) have not been subjected to rigorous empirical evaluation $[20,38,39]$. The histogram of number of symptoms for both males and females suggest quantitative differences by number of symptoms rather than the qualitative difference between 0-3 and 4-8 symptoms implied by the CDC-94 criteria [23]. 
Of note, subjects with any self-reported lifetime chronic fatiguing condition had far worse functional status than their nonfatigued counterparts. Both the physical and mental health subscale scores of the SF-12 [24] were over a standard deviation worse than people who denied any lifetime fatigue. This finding is consistent with a recent review by Ross et al. [40] that reported the results of numerous studies that assessed the functional status of patients with CFS using a related scale (SF-36) and underscores the substantial morbidity associated with these syndromes.

This study has several key limitations. First, our scientific aims to analyze questionnaire items on fatigue-related conditions obtained from a large twin registry were thwarted when the larger societal issue of personal privacy intersected with the research approaches operationalized at Virginia Commonwealth University and in the MATR[28,29]. This issue, which remains incompletely resolved, effectively led to the premature termination of this study. It is difficult to know how the low response may have biased our results-for example, one can argue that subjects with chronic fatigue may have been both more likely to respond (due to greater interest in this topic) as well as less likely to respond (due to fatigability). Second, our assessment of fatiguing illnesses was derived from questionnaires; no physical examination was performed and no additional medical or psychiatric evaluations were available to classify participants. It is assuring, however, that the prevalences reported here were similar to those found in the literature. Finally, as our data was cross-sectional, we could not address the etiology of fatiguing illnesses. Our findings are thus qualified; however, given the relative paucity of data on chronic fatiguing illness, we argue that these data contain information relevant to the field. Furthermore, our report extends the prior literature by focusing on lifetime definitions of fatiguing illness rather than symptoms in the prior 6 months.

In summary, we observed striking differences in the rates and severity of fatiguing illness between men and women. Women are burdened with a higher prevalence of fatiguing illnesses that appear at earlier ages with debilitating functional consequences. Which of these differences are important and how they function mechanistically should serve as the next steps for elucidating the persistent conundrum of fatigue.

\section{Acknowledgments}

This work was supported by AI-038429 (D. Buchwald, principal investigator).

\section{References}

[1]. Pawlikowska T, Chalder T, Hirsch SR, Wallace P, Wright DJM, Wessely SC. Population based study of fatigue and psychological distress. BMJ 1994;308:763-6. [PubMed: 7908238]

[2]. David A, Pelosi A, McDonald E, Stephens D, Ledger D, Rathbone R, Mann A. Tired, weak, or in need of rest: fatigue among general practice attenders. BMJ 1990;301:1199-202. [PubMed: 2261560]

[3]. Lewis G, Wessely S. The epidemiology of fatigue: more questions than answers. J Epidemiol Community Health 1992;46:92-7. [PubMed: 1583440]

[4]. Jason LA, Richman JA, Rademaker AW, Jordan KM, Plioplys AV, Taylor RR, McCready W, Huang $\mathrm{CF}$, Plioplys S. A community-based study of chronic fatigue syndrome. Arch Intern Med 1999;159:2129-37. [PubMed: 10527290]

[5]. Reyes M, Nisenbaum R, Hoaglin DC, Unger ER, Emmons C, Randall B, Stewart JA, Abbey S, Jones JF, Gantz N, Minden S, Reeves WC. Prevalence and incidence of chronic fatigue syndrome in Wichita, Kansas. Arch Intern Med 2003;163(13):1530-6. [PubMed: 12860574]

[6]. Wessely S, Chalder T, Hirsch S, Wallace P, Wright D. The prevalence and morbidity of chronic fatigue and chronic fatigue syndrome: a prospective primary care study. Am J Public Health 1997;87 (9):1449-55. [PubMed: 9314795] 
[7]. Buchwald D, Pearlman T, Umali J, Schmaling K, Katon W. Functional status in patients with chronic fatigue syndrome, other fatiguing illness, and healthy individuals. Am J Med 1996;101:364-70. [PubMed: 8873506]

[8]. Bombardier CH, Buchwald D. Chronic fatigue, chronic fatigue syndrome, and fibromyalgia. Med Care 1996;34:924-30. [PubMed: 8792781]

[9]. Komaroff AL, Fagioli LR, Doolittle TH, Gandek B, Gleit MA, Guerriero RT, Kornish RJ, Ware NC, Ware JE, Bates DW. Health status in patients with chronic fatigue syndrome and in general population and disease comparison groups. Am J Med 1996;101:281-90. [PubMed: 8873490]

[10]. Fukuda K, Dobbins JG, Wilson LJ, Dunn RA, Wilcox K, Smallwood D. An epidemiological study of fatigue with relevance for the chronic fatigue syndrome. J Psychiatr Res 1997;31:19-29. [PubMed: 9201644]

[11]. Lindal E, Stafansson JG, Bergman S. The prevalence of chronic fatigue syndrome in Iceland. Nord J Psychiatry 2002;56:272-7.

[12]. Price RK, North CS, Wessely S, Fraser VJ. Estimating the prevalence of chronic fatigue syndrome and associated symptoms in the community. Public Health Rep 1992;107:514-22. [PubMed: 1329134]

[13]. Steele L, Dobbins JG, Fukuda K, Reyes M, Randall B, Koppelman M, Reeves WC. The epidemiology of chronic fatigue in San Francisco. Am J Med 1998;105(3A):83S-90S. [PubMed: 9790487]

[14]. Lloyd AR, Hickie I, Boughton CR, Spencer O, Wakefield D. Prevalence of chronic fatigue syndrome in an Australian population. Med J Aust 1990;153(9):522-8. [PubMed: 2233474]

[15]. Bates DW, Schmitt W, Buchwald D, Ware NC, Lee J, Thoyer E, Kornish RJ, Komaroff AL. Prevalence of fatigue and chronic fatigue syndrome in a primary care practice. Arch Intern Med 1993;153(24):2759-65. [PubMed: 8257251]

[16]. Buchwald D, Umali P, Umali J, Kith P, Pearlman T, Komaroff AL. Chronic fatigue and the chronic fatigue syndrome: prevalence in a Pacific Northwest health care system. Ann Intern Med 1995;123 (2):81-8. [PubMed: 7778839]

[17]. Lawrie SM, Pelois AJ. Chronic fatigue syndrome in the community: prevalence and associations. Br J Psychiatry 1995;166:793-7. [PubMed: 7663830]

[18]. Chester AC. Chronic fatigue syndrome criteria in patients with other forms of unexplained chronic fatigue. J Psychiatr Res 1997;31(1):45-50. [PubMed: 9201646]

[19]. Gunn WJ, Connell DB, Randall B. Epidemiology of chronic fatigue syndrome: the Centers for Disease Control Study. Ciba Found Symp 1993;173:83-93. [discussion 93-101]. [PubMed: 8387910]

[20]. Komaroff AL, Buchwald DS. Chronic fatigue syndrome: an update. Annu Rev Med 1998;49:1-13. [PubMed: 9509246]

[21]. Sharpe M. Chronic fatigue syndrome. Psychiatr Clin N Am 1996;19:549-73.

[22]. Anderson LS, Beverly WT, Corey LA, Murrelle L. The Mid-Atlantic Twin Registry. Twin Res 2002;5(5):449-55. [PubMed: 12537875]

[23]. Fukuda K, Strauss SE, Hickie I, Sharpe MC, Dobbins JG, Komaroff A. The chronic fatigue syndrome: a comprehensive approach to its definition and study. Ann Intern Med 1994;121:9539. [PubMed: 7978722]

[24]. Ware J, Kosinski M, Keller SD. A 12-Item Short-Form Health Survey: construction of scales and preliminary tests of reliability and validity. Med Care 1996;34:220-33. [PubMed: 8628042]

[25]. American Psychiatric Association. Diagnostic and statistical manual of mental disorders. 4th ed. American Psychiatric Association; Washington (DC): 1994.

[26]. Kendler KS, Pedersen NL, Neale MC, Mathé A. A pilot Swedish twin study of affective illness including hospital- and population-ascertained subsamples: results of model fitting. Behav Genet 1995;25:217-32. [PubMed: 7598665]

[27]. Kendler KS, Pedersen N, Johnson L, Neale MC, Mathe AA. A pilot Swedish twin study of affective illness, including hospital- and population-ascertained subsamples. Arch Gen Psychiatry 1993;50 (9):699-700. [PubMed: 8357295]

[28]. Botkin J. Protecting the privacy of family members in survey and pedigree research. JAMA 2001;285(2):207-11. [PubMed: 11176815] 
[29]. Mathews J. Father's complaints shut down research: US agencies act on privacy concerns. Washington Post. Dec 1;2000 Sect. B7.

[30]. SAS Institute. SAS/STAT software. version 8. SAS Institute; Cary (NC): 1999.

[31]. MathSoft. S-Plus 5 for UNIX guide to statistics. MathSoft; Seattle (Wash): 2000.

[32]. Stokes; Davis, C.; Koch, G. Categorical data analysis using SAS. SAS Institute; Cary (NC): 1995.

[33]. Cox, DR.; Oakes, D. Analysis of survival data. Chapman \& Hall; London: 1984.

[34]. Allison, PD. Survival analysis using the SAS system: a practical guide. SAS Institute; Cary (NC): 1995.

[35]. Kang HK, Natelson B, Mahan CM, Lee KY, Murphy FM. Posttraumatic stress disorder and chronic fatigue syndrome-like illness among Gulf War veterans. Am J Epidemiol 2003;157:141-8. [PubMed: 12522021]

[36]. Harlow BL, Signorello LB, Hall JE, Dailey C, Komaroff AL. Reproductive correlates of chronic fatigue syndrome. Am J Med 1998;105(3A):94S-9S. [PubMed: 9790489]

[37]. Glaser R, Kiecolt-Glaser JK. Stress-associated immune modulation: relevance to viral infections and chronic fatigue syndrome. Am J Med 1998;105(3A):35S-42S. [PubMed: 9790480]

[38]. Buchwald D. Fibromyalgia and chronic fatigue syndrome. Rheum Dis Clin North Am 1996;22:21943. [PubMed: 9157484]

[39]. Levine PH. Epidemiologic advances in chronic fatigue syndrome. J Psychiatr Res 1997;31:7-18. [PubMed: 9201643]

[40]. Ross SD, Estok RP, Frame D, Stone LR, Ludensky V, Levine CB. Disability and chronic fatigue syndrome: a focus on function. Arch Intern Med 2004;164(10):1098-107. [PubMed: 15159267] 


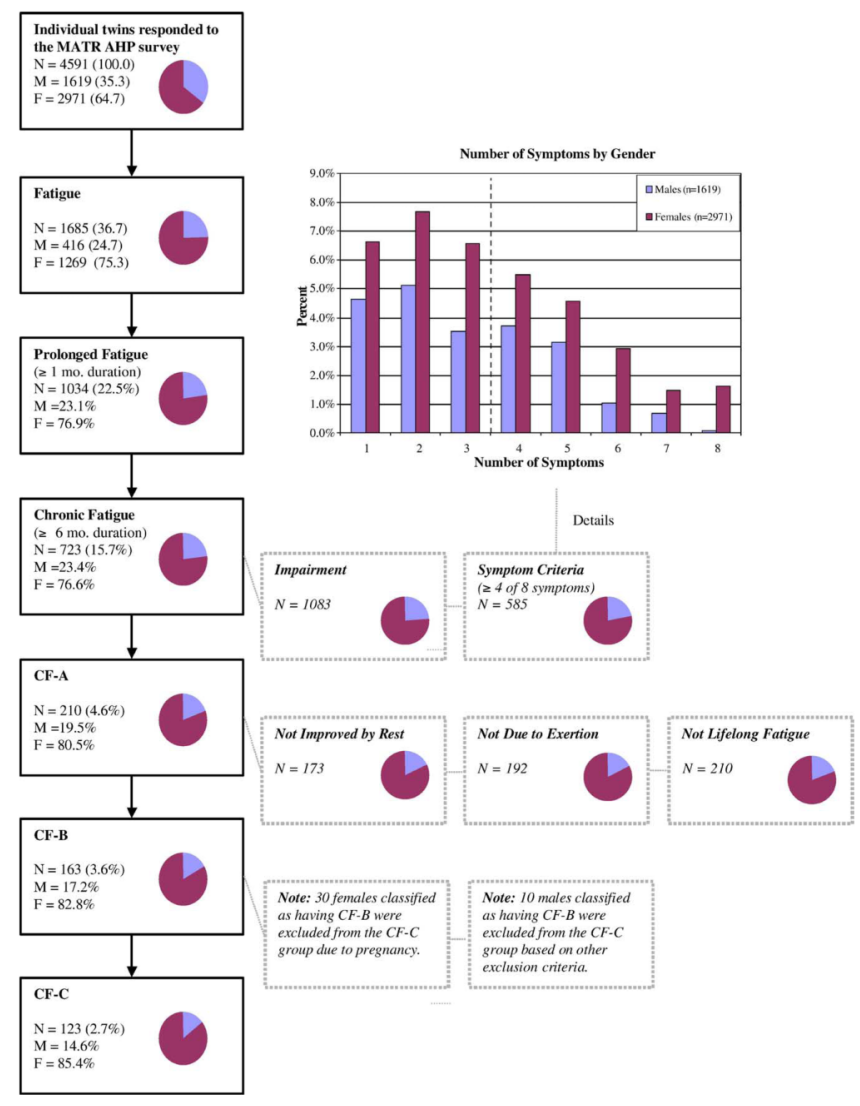

Fig. 1.

Flowchart depicting the definitions of lifetime fatigue-related conditions arranged in increasing severity (top to bottom) in the MATR. The pie charts in each box show the proportion of males (light purple) and females (dark purple). Details regarding symptom histogram and exclusionary conditions are shown. 


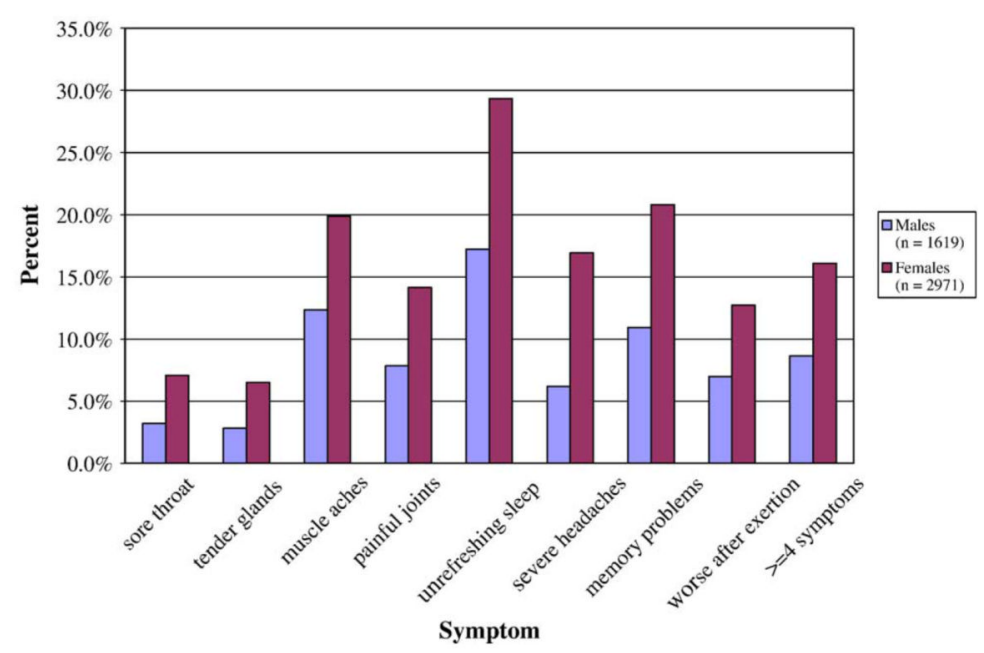

Fig. 2.

Distributions of specific symptoms reported by males (light purple) and females (dark purple) in the MATR. The $x$-axis depicts the eight symptoms asked of participants. The final column on the $x$-axis represents how many males and females endorsed having $\geq 4$ symptoms. The $y$ axis represents the proportion of participants that answered "yes" to having the specific symptom. 

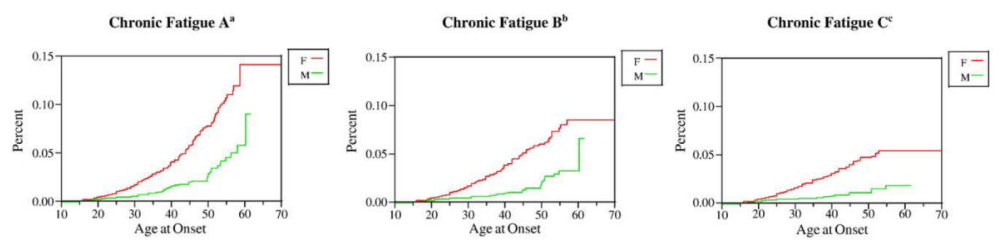

"Median age at onsel for CF-A was 31.0 years for females, 31.0 years for males.

"Median age at onset for CF-B was 31.0 years for females, 33.5 years for males.
'Median age at onset for CF-C was 32.0 years for females, 33.5 years for males.

Fig. 3.

Age at onset curves for lifetime fatigue-related conditions of increasing severity stratified by gender. The $y$-axis depicts the proportion of the sample that had not developed a particular definition of fatigue. The $x$-axis depicts participant age in years. The green line shows the male estimates, while the red line shows the female estimates. For each fatigue definition, the male and female age at onset curves were different at the $P<.001$ for both the Wilcoxon and $\log -$ rank tests after correction for nonindependence of twin pairs. 
Table 1

Prevalence of lifetime fatigue-related conditions by gender among MATR study participants

\begin{tabular}{|c|c|c|c|c|}
\hline \multirow[b]{2}{*}{$\begin{array}{l}\text { Fatigue } \\
\text { definition } a\end{array}$} & \multicolumn{3}{|c|}{ Frequency (\%) } & \multirow[b]{2}{*}{$\begin{array}{c}\text { OR } \\
(95 \% \mathrm{CI})^{b}\end{array}$} \\
\hline & $\begin{array}{l}\text { All } \\
(n=4591)\end{array}$ & $\begin{array}{l}\text { Females } \\
(n=2971)\end{array}$ & $\underset{(n=1619)}{\text { Males }}$ & \\
\hline $\begin{array}{l}\text { Chronic } \\
\text { fatigue }\end{array}$ & $723(15.7)$ & 554 (18.6) & $169(10.4)$ & $2.0(1.6-2.4)$ \\
\hline $\begin{array}{l}\text { Chronic } \\
\text { fatigue A }\end{array}$ & $210(4.6)$ & $169(5.7)$ & $41(2.5)$ & $2.3(1.6-3.3)$ \\
\hline $\begin{array}{l}\text { Chronic } \\
\text { fatigue B }\end{array}$ & $163(3.6)$ & 135 (4.6) & $28(1.7)$ & $2.7(1.8-4.1)$ \\
\hline $\begin{array}{l}\text { Chronic } \\
\text { fatigue } \mathrm{C}\end{array}$ & $123(2.7)$ & $105(3.5)$ & $18(1.1)$ & $3.3(2.0-5.4)$ \\
\hline
\end{tabular}

${ }^{a}$ Chronic fatigue was defined as $\geq 6$ months of fatigue; chronic fatigue A added the presence of impairment and presence of four of eight ancillary symptoms; chronic fatigue B included participants with chronic fatigue A whose fatigue was not due to exertion, not alleviated by rest and not lifelong; chronic fatigue $\mathrm{C}$ included participants with chronic fatigue $\mathrm{B}$ who were not morbidly obese or have a medical illness that could explain fatigue.

${ }^{b}$ ORs and $95 \%$ CIs comparing females to males employing generalized estimating equations to account for the nonindependent clustering of members of a twin pair.

${ }^{c}$ One participant did not report gender. 
